\title{
The peak stress method applied to the fatigue assessment of tube-tube steel joints with weld ends under multiaxial loadings
}

\author{
Giovanni Meneghetti ${ }^{1,1}$, Alberto Campagnolo ${ }^{1}$, Michael Vormwald ${ }^{2}$ and Ehsan Shams ${ }^{2}$ \\ ${ }^{1}$ University of Padova, Department of Industrial Engineering, 35131 Padova, Italy \\ ${ }^{2}$ Technische Universität Darmstadt, Department of Civil and Environmental Engineering, Materials \\ Mechanics Group, 64287 Darmstadt, Germany
}

\begin{abstract}
The Peak Stress Method (PSM) is an approximate, FE-oriented application of the notch stress intensity factor (NSIF) approach to fatigue design of welded joints, which is based on the singular linear elastic peak stresses calculated from FE analyses performed by using coarse mesh patterns. By adopting the averaged strain energy density (SED) as a fatigue strength criterion, a design stress (the equivalent peak stress) can be defined; in conjunction with a reference design curve previously defined, the fatigue strength assessment of welded joints subjected to multiaxial fatigue loadings can be performed. In the present contribution, the PSM has been applied to the fatigue assessment of tube-tube steel joints with weld ends, which have been fatigue tested in a previous contribution under combined loadings: namely pure axial, pure torsion and in-phase as well as out-of-phase axialtorsion loadings, all of which with two load ratios, i.e. $\mathrm{R}=0$ and $\mathrm{R}=-1$. The experimental fatigue results have been re-converted in terms of equivalent peak stress by adopting a 3D FE model including an idealised weld end geometry. The equivalent peak stress has proved to assess the fatigue crack initiation location in agreement with experimental observations, moreover a quite good agreement has been obtained between the experimental results and the PSM-based design scatter band.
\end{abstract}

\section{Introduction: NSIF-based local approaches}

The Notch Stress Intensity Factor (NSIF) based approaches for fatigue design of welded joints assume both the weld toe and root as sharp V-notches, having a notch tip radius $\rho=0$, that is the worst case condition, and notch opening angle greater than zero (typically $135^{\circ}$ ) and equal to zero, respectively [1-3]. Under these assumptions, the local, linear elastic stress fields close to the notch tip (see Fig. 1a) can be expressed as functions of the relevant NSIFs, 
which quantify the magnitude of the asymptotic singular stress distributions. NSIFs have been defined by Gross and Mendelson [4] as follows:

$\mathrm{K}_{\mathrm{i}}=\sqrt{2 \pi} \cdot \lim _{\mathrm{r} \rightarrow 0}\left[\left(\sigma_{\mathrm{jk}}\right)_{\theta=0} \cdot \mathrm{r}^{1-\lambda_{\mathrm{i}}}\right] \quad$ where $\mathrm{i}=1,2,3 \quad$ and $\quad \sigma_{\mathrm{jk}}=\sigma_{\theta \theta}, \tau_{\mathrm{r} \theta}, \tau_{\theta z}$ respectively

where $\lambda_{\mathrm{i}}$ is the stress singularity exponent tied to mode I, II and III for $\mathrm{i}=1,2$ and 3 , respectively, and it is dependent on the notch opening angle $2 \alpha$, while the stress components $\sigma_{\theta \theta}, \tau_{\mathrm{r} \theta}$ and $\tau_{\theta \mathrm{z}}$ are referred to the notch bisector line $(\theta=0$ in Fig. $1 \mathrm{a})$.
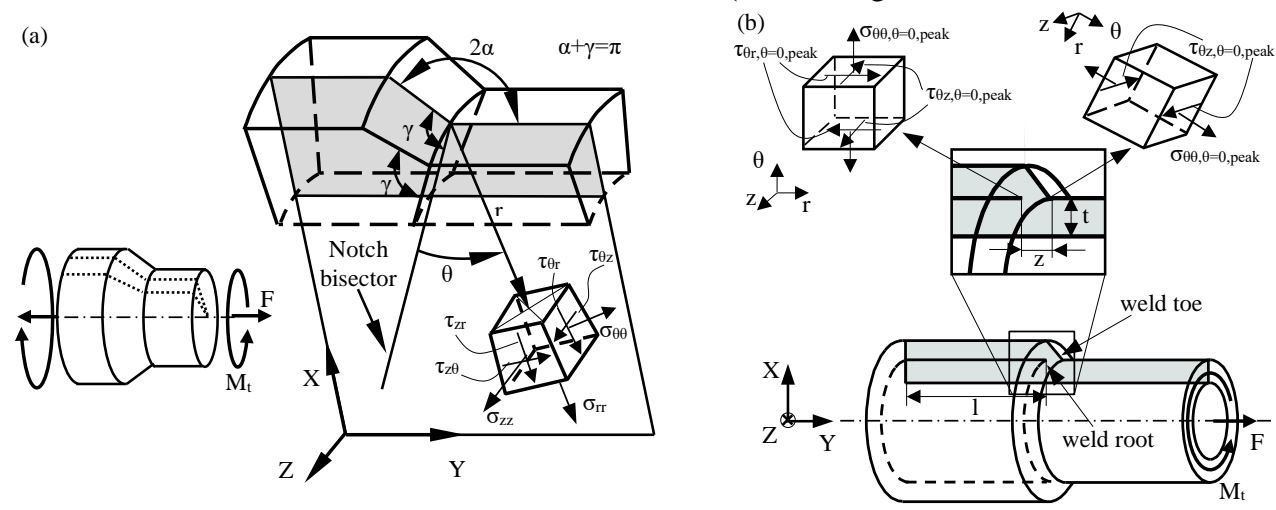

Fig 1: (a) Polar reference system centred at the weld toe of a typical tube-tube welded joint geometry subjected to combined axial and torsion loadings. (b) Sharp V-shaped notches in a tube-tube welded joint at the weld root $\left(2 \alpha=0^{\circ}\right)$ and at the weld toe (2 $\alpha$ typically equal to $\left.135^{\circ}\right)$ sides. Definition of peak

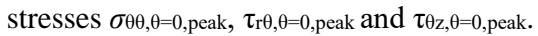

NSIFs are local stress parameters, therefore they allow by nature to correlate fatigue life including initiation and propagation of a short crack inside the region of material where stress distributions are governed by the NSIFs leading terms. Even though the mode I NSIF proved to correlate weld toe failures with constant notch opening angle $2 \alpha$ [1], direct comparability of the NSIFs is not possible when different opening angles $2 \alpha$ are considered, since the NSIFs units in Eq. (1) change with $2 \alpha$. This happens for example when fatigue criticality is comparatively evaluated at the weld toe and at the weld root. The strain energy density averaged over a structural volume surrounding the weld root or the weld toe, as proposed by Lazzarin and co-workers [5], may be invoked to restore the comparability. Lazzarin et al. [5] assumed a structural volume having circular shape with radius $\mathrm{R}_{0}$ and provided the closedform expression of the averaged SED parameter as a function of the relevant NSIFs. Concerning a general multiaxial fatigue loading condition (mixed mode I+II+III loading, see Fig. 1), the SED averaged over the structural volume can be expressed as follows [5]:

$\Delta \bar{W}=c_{w 1} \frac{e_{1}}{E}\left[\frac{\Delta K_{1}}{R_{0}^{1-\lambda_{1}}}\right]^{2}+c_{w 2} \frac{e_{2}}{E}\left[\frac{\Delta K_{2}}{R_{0}^{1-\lambda_{2}}}\right]^{2}+c_{w 3} \frac{e_{3}}{E}\left[\frac{\Delta K_{3}}{R_{0}^{1-\lambda_{3}}}\right]^{2}$

In previous expression, $\mathrm{E}$ is the Young's modulus, $\mathrm{e}_{1}, \mathrm{e}_{2}$ and $\mathrm{e}_{3}$ are known parameters which are functions of the notch opening angle $2 \alpha$ and of the Poisson's ratio $v$ (see [5]), while $\Delta \mathrm{K}_{1}, \Delta \mathrm{K}_{2}$ and $\Delta \mathrm{K}_{3}$ are the ranges (maximum value minus minimum value) of the NSIFs relevant to mode I, II and III, respectively. Concerning arc-welded joints made of structural steel, the structural volume size $R_{0}$ was calibrated and found to be $0.28 \mathrm{~mm}$ [6]. Finally, the parameters $c_{\text {wi }}$ ( $\mathrm{i}=1,2,3$ indicates the loading mode) account for the effect of the nominal load ratio $R$ according to Eq. (3) [7], which provides the following master cases: $c_{\mathrm{w}}=0.5$ for $R=-1$ and $c_{\mathrm{w}}=1$ for $R=0$. It is worth noting that welded joints loaded in the as-welded 
conditions are almost insensitive to mean stresses, according to fatigue design standards [8], accordingly Eq. (2) with $c_{\mathrm{wi}}=1$ should be applied.

$C_{w}(R)=\left\{\begin{array}{lll}\frac{1+R^{2}}{(1-R)^{2}} & \text { if } & -1 \leq R \leq 0 \\ \frac{1-R^{2}}{(1-R)^{2}} & \text { if } & 0<R<1\end{array}\right.$

The application of the NSIF approach in engineering problems presents a major drawback, due to the need of very refined FE meshes in order to evaluate the NSIFs on the basis of their definitions, Eq. (1). In the case of three-dimensional components, the numerical analyses could be even more time-consuming. Lazzarin and co-workers showed that the averaged SED can be calculated directly by FEM adopting coarse meshes within the structural volume having radius $R_{0}$ according to the so-called “direct approach" [9]:

$\Delta \overline{\mathrm{W}}=\frac{\sum_{\mathrm{V}\left(\mathrm{R}_{0}\right)} \mathrm{W}_{\mathrm{FEM}, \mathrm{i}}}{\mathrm{V}\left(\mathrm{R}_{0}\right)}$

Alternatively, the Peak Stress Method (PSM) could be adopted to rapidly estimate the NSIFs by FEM adopting even coarser meshes [10] without the need to model the structural volume of radius $R_{0}$. Furthermore, the PSM requires only the singular, linear elastic peak stresses evaluated at the V-notch tip, instead of a number of stress-distance FE results, as required by the definitions of NSIFs, Eq. (1). Essentially, the PSM allows to rapidly estimate the NSIFs $K_{1}, K_{2}$ and $K_{3}$ from the singular, linear elastic, opening, sliding and anti-plane FE peak stresses $\sigma_{\theta \theta, \theta=0 \text {,peak }}, \tau_{\mathrm{r} \theta, \theta=0 \text {,peak }}$ and $\tau_{\theta z, \theta=0 \text {,peak }}$, respectively. The stresses refer to the $V$-notch bisector line (see Fig. 1b) at the V-notch tip from FE analyses with coarse meshes. The relevant expressions are as follows [10-12]:

$\mathrm{K}_{1} \cong \mathrm{K}_{\mathrm{FE}}^{*} \sigma_{\theta \theta, \theta=0, \text { peak }} \mathrm{d}^{1-\lambda_{1}} ; \quad \mathrm{K}_{2} \cong \mathrm{K}_{\mathrm{FE}}^{* *} \tau_{\mathrm{r} \theta, \theta=0, \text { peak }} \mathrm{d}^{0.5} ; \quad \mathrm{K}_{3} \cong \mathrm{K}_{\mathrm{FE}}^{* * *} \tau_{\theta z, \theta=0, \text { peak }} \mathrm{d}^{1-\lambda_{3}}$

In previous expressions, $d$ is the so-called 'global element size' parameter to input in Ansys ${ }^{\circledR}$ software, i.e. the mean size of the finite elements adopted by the free mesh generation algorithm available in the FE code. The average values of 1.38, 3.38 and 1.93 were derived for the constants $\mathrm{K}_{\mathrm{FE}}^{*}, \mathrm{~K}_{\mathrm{FE}}^{* *}$ and $\mathrm{K}_{\mathrm{FE}}^{* * *}$, respectively, under the conditions summarised in Table 1 and discussed in more detail in the relevant literature [10-12], to which the reader is referred.

Equations (5a-c) are useful for a design engineer, since they allow a rapid estimation of the NSIFs $K_{1}, K_{2}$ and $K_{3}$ by taking advantage of the FE peak stresses $\sigma_{\theta \theta, \theta=0, \text { peak }}, \tau_{\mathrm{r} \theta, \theta=0 \text {,peak }}$ and

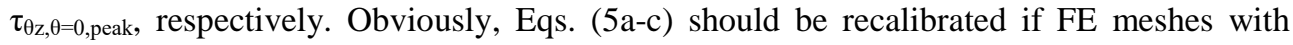
higher-order finite elements or significantly different mesh patterns as compared to the reference one (see the original papers [10-12] and 'mesh pattern' in Table 1) were adopted.

It is worth noting that by using the PSM-based relationships (Eqs. (5a-c)), the closedform expression of the averaged SED, Eq. (2), can be re-written as a function of the singular,

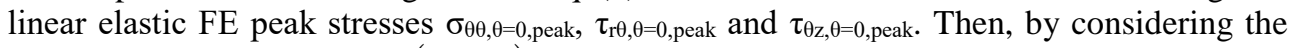
strain energy equality $\mathrm{W}=\left(1-v^{2}\right) \cdot \sigma_{\text {eq, peak }}^{2} / 2 \mathrm{E}$ valid under plane strain conditions, an equivalent peak stress, $\sigma_{\text {eq,peak }}$, can be defined: 


$$
\begin{aligned}
& \Delta \overline{\mathrm{W}}=\mathrm{c}_{\mathrm{w} 1} \frac{\mathrm{e}_{1}}{\mathrm{E}}\left[\mathrm{K}_{\mathrm{FE}}^{*} \cdot \Delta \sigma_{\theta \theta, \theta=0, \text { peak }} \cdot\left(\frac{\mathrm{d}}{\mathrm{R}_{0}}\right)^{1-\lambda_{1}}\right]^{2}+\mathrm{c}_{\mathrm{w} 2} \frac{\mathrm{e}_{2}}{\mathrm{E}}\left[\mathrm{K}_{\mathrm{FE}}^{* *} \cdot \Delta \tau_{\mathrm{r} \theta, \theta=0, \text { peak }} \cdot\left(\frac{\mathrm{d}}{\mathrm{R}_{0}}\right)^{1-\lambda_{2}}\right]^{2}+ \\
& \mathrm{c}_{\mathrm{w} 3} \frac{\mathrm{e}_{3}}{\mathrm{E}}\left[\mathrm{K}_{\mathrm{FE}}^{* * * *} \cdot \Delta \tau_{\theta z, \theta=0, \text { peak }} \cdot\left(\frac{\mathrm{d}}{\mathrm{R}_{0}}\right)^{1-\lambda_{3},}\right]^{2} \rightarrow=\frac{1-v^{2}}{2 \mathrm{E}} \Delta \sigma_{\text {eq,peak }}^{2}
\end{aligned}
$$

Accordingly, the equivalent peak stress for a general multiaxial loading condition results as follow $[13,14]$ :

$$
\Delta \sigma_{\text {eq,peak }}=\sqrt{\mathrm{c}_{\mathrm{w} 1} \cdot \mathrm{f}_{\mathrm{w} 1}^{2} \cdot \Delta \sigma_{\theta \theta, \theta=0, \text { peak }}^{2}+\mathrm{c}_{\mathrm{w} 2} \cdot \mathrm{f}_{\mathrm{w} 2}^{2} \cdot \Delta \tau_{\mathrm{r} \theta, \theta=0, \text { peak }}^{2}+\mathrm{c}_{\mathrm{w} 3} \cdot \mathrm{f}_{\mathrm{w} 3}^{2} \cdot \Delta \tau_{\theta z, \theta=0, \text { peak }}^{2}}
$$

The coefficients $f_{w i}$ (i $=1,2,3$ indicates the loading mode) in Eq. (7) weight the peak stresses both around the notch tip and along the radial direction, i.e. $\theta$ and $r$ coordinates, respectively, in Fig. 1. The parameters $f_{w i}$ are defined as follows:

$\mathrm{f}_{\mathrm{wi}}=\mathrm{K}_{\mathrm{FE}} \cdot \sqrt{\frac{2 \mathrm{e}_{\mathrm{i}}}{1-\mathrm{v}^{2}}} \cdot\left(\frac{\mathrm{d}}{\mathrm{R}_{0}}\right)^{1-\lambda_{\mathrm{i}}} \quad$ where $\mathrm{i}=1,2,3$

It should be noted that while both the coefficients $f_{w i}$ and the peak stresses of Eq. (7) depend on the average element size $d$, the equivalent peak stress does not.

Alternatively, if the "direct approach" according to Eq. (4) is adopted to calculate the averaged SED, the equivalent peak stress, $\sigma_{\text {eq,peak, }}$ can be defined as follows:

$$
\Delta \sigma_{\text {eq,peak }}=\sqrt{\frac{2 \mathrm{E}}{1-v^{2}} \cdot \Delta \overline{\mathrm{W}}}
$$

\begin{tabular}{|c|c|c|c|}
\hline & \multicolumn{3}{|l|}{ Loading mode } \\
\hline & Mode I & Mode II & Mode III \\
\hline Eq. & (5a) & (5b) & $(5 c)$ \\
\hline $\mathrm{K}_{\mathrm{FE}}$ & $1.38 \pm 3 \%$ & $3.38 \pm 3 \%$ & $1.93 \pm 3 \%$ \\
\hline 3D FE & \multicolumn{3}{|c|}{ SOLID 45 or SOLID 185 (K-option 2 set to 3 ) } \\
\hline Mesh pattern & \multicolumn{3}{|c|}{$\begin{array}{l}4 \text { elements share the node at the notch tip if } 2 \alpha \leq 90^{\circ} \\
2 \text { elements share the node at the notch tip if } 2 \alpha>90^{\circ}\end{array}$} \\
\hline $2 \alpha$ & $0^{\circ} \leq 2 \alpha \leq 135^{\circ}$ & $2 \alpha=0^{\circ}$ & $0^{\circ} \leq 2 \alpha \leq 135^{\circ}$ \\
\hline Minimum $a / d$ & 3 & 14 & $\begin{array}{l}3\left(\text { toe, } 2 \alpha \cong 135^{\circ}\right) \\
12\left(\text { root, } 2 \alpha=0^{\circ}\right)\end{array}$ \\
\hline$a-$ root side* & $a=\min \{l, z\}$ & $a=\min \{l, z\}$ & $a=\min \{l, z, t\}$ \\
\hline$a-$ toe side $^{*}$ & $a=t$ & - & $a=t$ \\
\hline
\end{tabular}

Table 1: Conditions for applicability of Eqs. (5a-c) by using Ansys ${ }^{\circledR}$ FE code [10-12].

\section{Tube-tube steel joints with weld ends: geometry and FE stress analyses according to the PSM approach}

The PSM according to Eqs. (7) and (9) has been applied in the present contribution to reanalyse experimental fatigue results generated by Shams and Vormwald [15] by testing tubetube steel joints with weld ends under axial, torsion and combined in-phase as well as out- 
of-phase axial-torsion loadings. Table 2 reports the geometry of the considered joints. For details about materials, welding processes and testing conditions, the reader is referred to [15].

In reference [15] the numerical fatigue assessment has been based on the notch stress approach. Notch radii of $0.2 \mathrm{~mm}$ and $0.05 \mathrm{~mm}$ have been introduced. Further, methods for taking the size effect [16,17] have been applied as well as a multiaxial failure hypothesis [18], leading to a considerable numerical effort. In the notch stress approach, the location of maximum stresses differ considerably for both loading cases. Consequently, both loading cases do not influence each other very much in the numeric - despite what is observed in the experiments.

Table 2: Joint geometry and FE analyses for fatigue strength assessment according to PSM

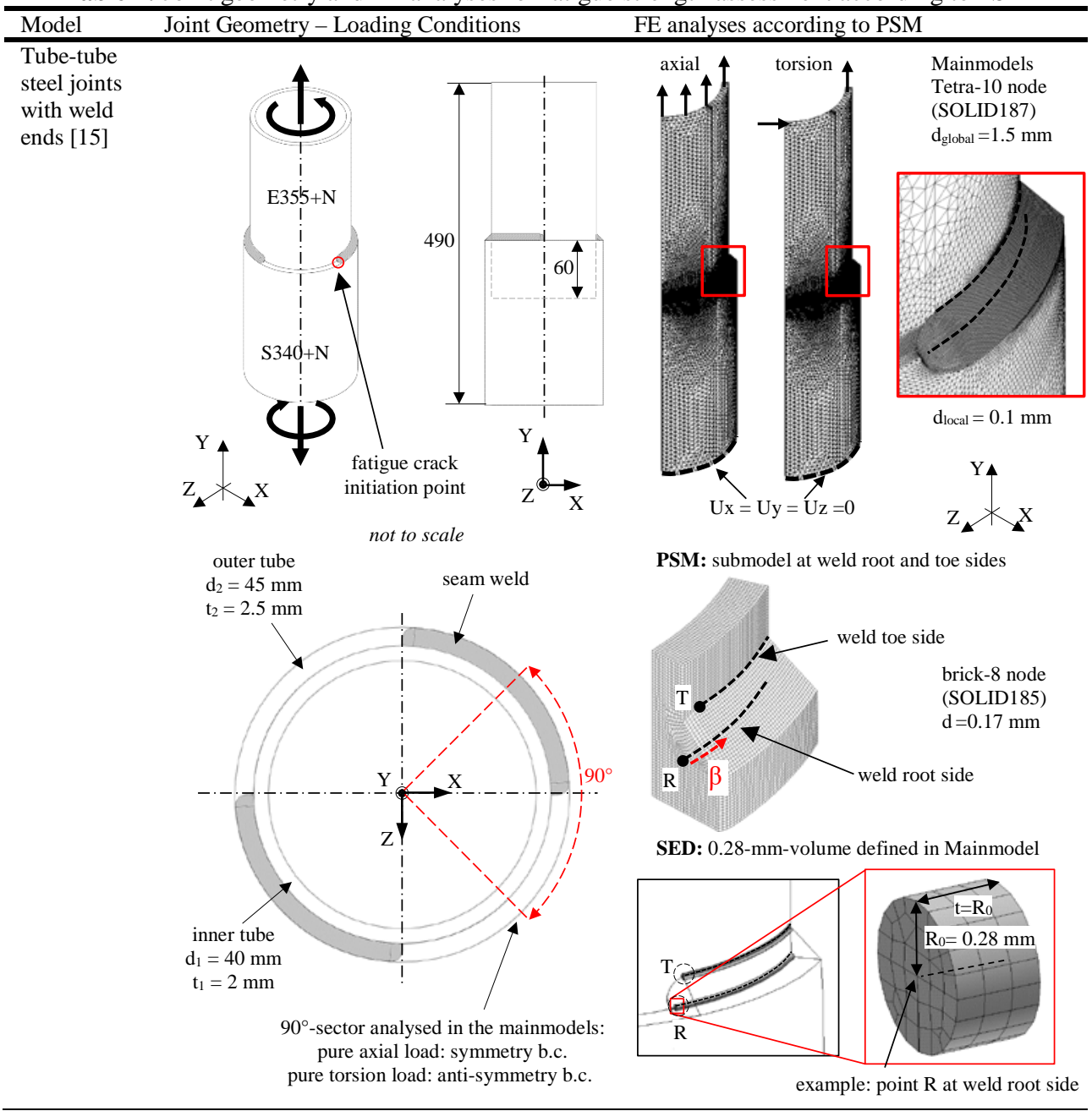

For the sake of brevity, only few details about the analysis procedure according to PSM are reported here. 3D FE analyses have been performed to calculate peak stresses according to the three-dimensional PSM [19]: first a FE analysis of the joint geometry was carried out by means of a main model; subsequently, a submodel of the critical area of the joint was analysed by adopting the submodelling technique available in Ansys ${ }^{\circledR}$ software. Table 2 shows that the main model consisted only of a $90^{\circ}$-sector of the specimen, since symmetry and anti-symmetry boundary conditions have been employed under axial and torsion loading, 
respectively. The main model was meshed by employing a free mesh of second-order, tennode tetra elements (SOLID 187 of the Ansys ${ }^{\circledR}$ element library) and by adopting a minimum element size equal to $0.1 \mathrm{~mm}$, which was dictated by the rather complex shape of the weld seam, even if the idealised geometry has been modeled according to [15]. Then, the submodel was defined by cutting the main model at a distance from the weld toe and the weld root equal to the tube thickness. The mesh density ratio must be $a / d \geq 14$ to satisfy the conditions of applicability of the PSM at the weld root under mode II loadings (see Table 1). The ligament length being $a=2.5 \mathrm{~mm}$, then the average element size $d$ has been set to $2.5 / 14 \approx$ $0.17 \mathrm{~mm}$. To obtain the 3D mesh of the submodel, a 2D free mesh pattern of quadrilateral four-node PLANE 182 elements having average size $d$ was generated in order to obtain the standard 2D mesh pattern required by the PSM (see Table 1 and [10-12]). Subsequently, the 2D FE mesh was swept by setting an extrusion step size equal to the average element size $d$ and by using 3D eight-node brick elements (SOLID185 of Ansys ${ }^{\circledR}$ element library with simple enhanced strain formulation activated, i.e. K-option 2 set to 3).
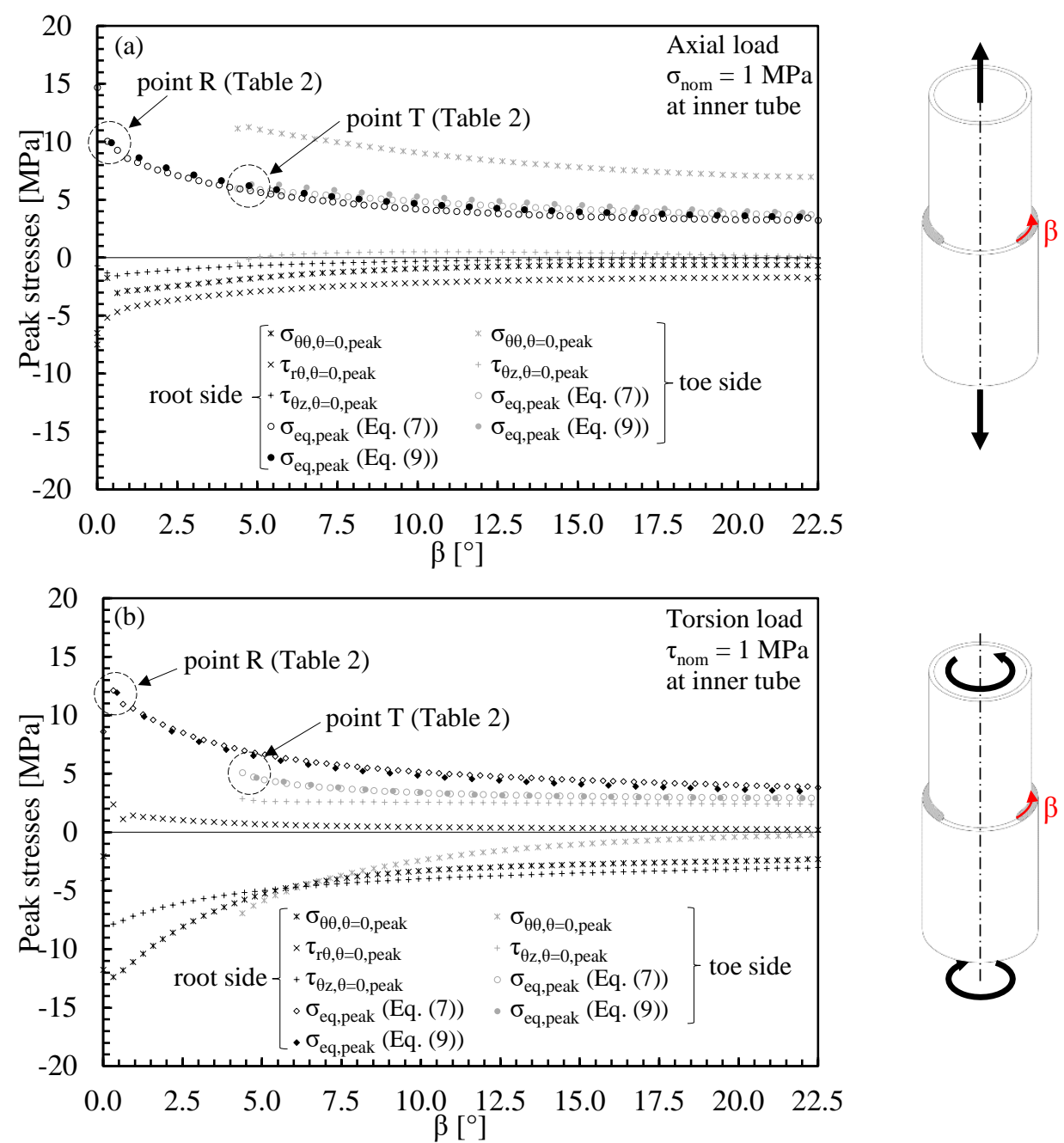

Fig. 2: Estimation of the crack initiation point based on the distribution of the equivalent peak stress along the weld root and weld toe lines of tube-tube steel joints with weld ends under (a) axial and (b) torsion loadings. 
After solving the submodels, the peak stresses $\sigma_{\theta \theta, \theta=0 \text {,peak }}, \tau_{\mathrm{r} \theta, \theta=0 \text {,peak }}$ and $\tau_{\theta z, \theta=0 \text {,peak }}$ have been calculated along the weld root and toe lines and have been reported in Fig. 2a and b referring to axial and torsion loadings, respectively. Figures 2a and 2b show that peak stresses increase their intensity moving towards the weld end; moreover, it can be observed that at the root side mode I and mode II peak stresses $\left(\sigma_{\theta \theta, \theta=0 \text {,peak }}\right.$ and $\left.\tau_{\mathrm{r} \theta, \theta=0 \text {,peak }}\right)$ induce coupled mode III peak stresses $\left(\tau_{\theta z, \theta=0 \text {,peak }}\right)$ and vice versa. These phenomena are due to three-dimensional effects tied to corner point singularities, which have deeply been investigated by Pook [20]. Then, the equivalent peak stress range has been evaluated along the weld root and toe lines from Eq. (7). The obtained results, which include also coupled peak stresses, have been validated by calculating the equivalent peak stress also from Eq. (9), i.e. directly from the SED averaged over the $0.28-\mathrm{mm}$-structural-volume shown in Table 2, which intrinsically account for the contribution of coupled modes [21]. Finally, Figs. 2a and 2b show that the equivalent peak stress is maximum at point $\mathrm{R}$, i.e. at the root side close to the weld end (see Table 2), under both axial and torsion loadings. Therefore, according to PSM the crack initiation location is anticipated at point $\mathrm{R}$, which is in agreement with the experimental observations reported in [15].

\section{Assessment of weld root fatigue failures}

The original experimental results [15] have been converted from the nominal stress range to the range of equivalent peak stress evaluated at the point of crack initiation, i.e. point $\mathrm{R}$ at root side. The residual stress state in as-welded joints having not been measured in [15], only experimental results generated from stress-relieved joints have been considered in the PSMbased re-analysis in order to exclude uncertainties in the residual stress evaluation.

It has been argued [22] that in order to select the proper PSM-based design curve, the contribution to the equivalent peak stress of shear as compared to normal stresses must first be evaluated. To this aim, a local biaxiality ratio $\lambda_{\text {local }}$ has been defined as the ratio between the energy contributions tied to the shear modes of loading, i.e. mode II and III, and the energy contribution tied to the opening mode, i.e. mode I. Taking advantage of the peak stresses $\tau_{\mathrm{r} \theta, \theta=0, \text { peak }}, \tau_{\theta z, \theta=0 \text {,peak }}$ and $\sigma_{\theta \theta, \theta=0 \text {,peak }}$ the ratio $\lambda_{\text {local }}$ can be expressed as follows [22]:

$\lambda_{\text {local }}=\frac{\mathrm{f}_{\mathrm{w} 2}^{2} \cdot \Delta \tau_{\mathrm{r} \theta, \theta=0, \text { peak }}^{2}+\mathrm{f}_{\mathrm{w} 3}^{2} \cdot \Delta \tau_{\theta z, \theta=0, \text { peak }}^{2}}{\mathrm{f}_{\mathrm{w} 1}^{2} \cdot \Delta \sigma_{\theta \theta, \theta=0, \text { peak }}^{2}}$

Based on the local stress analysis of Fig. 2 , the ratio $\lambda_{\text {local }}$ calculated at the fatigue crack initiation point, i.e. at point $\mathrm{R}$ of the weld root, results in the range between 137 and infinite for axial and torsion loadings, respectively. These values being very high (see [22] for a more detailed discussion), the contribution due to shear (mode II + III) stresses is definitely predominant for all considered loading conditions. Therefore, the crack initiation experimental results have been compared in Fig. 3 with the PSM-based design scatter band valid for steel welded joints subjected to pure mode III loading [12] $(\mathrm{k}=5)$. Figure 3 shows that the PSM-based scatter band exhibits a certain degree of conservatism. The stress gradient effect along the $\beta$ direction (see Table 2) might have not been quantified correctly. The strain energy was averaged in a structural volume having size equal to $\mathrm{R}_{0}$ along the $\beta$ direction; however, this size has not been derived rigorously. In our opinion early crack propagation should be investigated, in order to quantify the short crack size both along the radial direction r (see figure 1) and along the $\beta$ direction (see Table 2). Unfortunately, since the original experimental data were generated out of the purpose to apply the PSM, such experimental information is not available. 


\section{Conclusions}

The peak stress method (PSM) employs the singular, linear elastic peak stresses evaluated at the weld toe and root sides by means of FE analyses with rather coarse meshes to rapidly estimate the mode I, mode II and mode III NSIFs. By using the PSM in combination with the averaged Strain Energy Density (SED) criterion, a so-called equivalent peak stress can be defined to assess either weld toe or weld root fatigue failures in conjunction with a design curve. The PSM has been applied to analyse weld root fatigue failures generated in a recent contribution by some of the present authors by testing tube-tube steel joints with weld ends under axial, torsion and combined axial-torsion loadings. The equivalent peak stress has proved to properly assess the fatigue crack initiation location in agreement with experimental observations. Moreover, the local stress analysis according to the PSM demonstrated prevailing shear (mode II + III) stresses for all considered loading conditions. Therefore, the experimental results have been compared with the PSM-based design scatter band, which had been calibrated previously for pure mode III loading; the crack initiation experimental results were seen to fall inside the design scatter band and rather on the safe side. Because of the coarse FE analyses required and simplicity of post-processing the calculated peak stresses, the PSM might be useful in the everyday design practice. The numerical expense is considerably less compared to time and effort when applying the notch stress approach. The PSM as presented here provides an additional advantage as it enforces the coupling of the damaging effects of both loading cases in a single peak stress value.

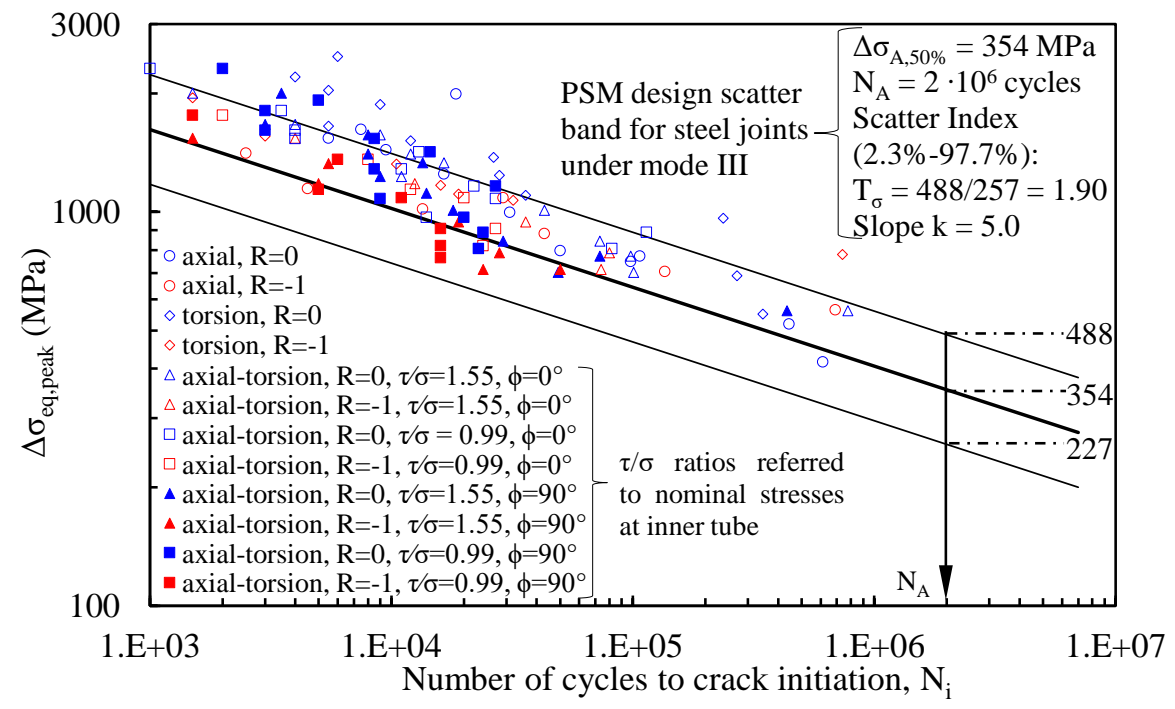

Fig. 3: Fatigue assessment of root failures in tube-tube steel joints with weld ends under axial, torsion and combined axial-torsion, in-phase $\left(\phi=0^{\circ}\right)$ and out-of-phase $\left(\phi=90^{\circ}\right)$, loadings according to the PSM.

\section{References}

1. P. Lazzarin, R. Tovo, A notch intensity factor approach to the stress analysis of welds, Fat. Fract. Eng. Mater. Struct., 21, 1089-1103. (1998)

2. D. Radaj, C.M. Sonsino, W. Fricke, Fatigue Assessment of Welded Joints by Local Approaches, Woodhead Publishing, Cambridge, (2006).

3. D. Radaj, M. Vormwald, Advanced Methods of Fatigue Assessment, Springer Berlin Heidelberg, Berlin, Heidelberg, (2013). 
4. B. Gross, A. Mendelson, Plane elastostatic analysis of V-notched plates, Int. J. Fract. Mech., 8, 267-276 (1972)

5. P. Lazzarin, P. Livieri, F. Berto, M. Zappalorto, Local strain energy density and fatigue strength of welded joints under uniaxial and multiaxial loading, Eng. Fract. Mech., 75, 1875-1889 (2008)

6. P. Livieri, P. Lazzarin, Fatigue strength of steel and aluminium welded joints based on generalised stress intensity factors and local strain energy values, Int. J. Fract., 133, 247-276 (2005)

7. P. Lazzarin, C.M. Sonsino, R. Zambardi, A notch stress intensity approach to assess the multiaxial fatigue strength of welded tube-to-flange joints subjected to combined loadings, Fat. Fract. Eng. Mater. Struct., 27, 127-140 (2004)

8. $\quad$ Eurocode 3: Design of steel structures - part 1-9: Fatigue, CEN, (2005).

9. P. Lazzarin, F. Berto, M. Zappalorto, Rapid calculations of notch stress intensity factors based on averaged strain energy density from coarse meshes: Theoretical bases and applications, Int. J. Fat., 32, 1559-1567. (2010)

10. G. Meneghetti, P. Lazzarin, Significance of the elastic peak stress evaluated by FE analyses at the point of singularity of sharp V-notched components, Fat. Fract. Eng. Mater. Struct., 30, 95-106 (2007)

11. G. Meneghetti, The use of peak stresses for fatigue strength assessments of welded lap joints and cover plates with toe and root failures, Eng. Fract. Mech., 89, 40-51 (2012)

12. G. Meneghetti, The peak stress method for fatigue strength assessment of tube-toflange welded joints under torsion loading, Weld. World., 57, 265-275 (2013)

13. G. Meneghetti, A. Campagnolo, D. Rigon, Multiaxial fatigue strength assessment of welded joints using the Peak Stress Method - Part I: Approach and application to aluminium joints, Int. J. Fat., 101, 328-342 (2017)

14. G. Meneghetti, A. Campagnolo, D. Rigon, Multiaxial fatigue strength assessment of welded joints using the Peak Stress Method - Part II: Application to structural steel joints, Int. J. Fat., 101, 343-362 (2017)

15. E. Shams, M. Vormwald, Fatigue of weld ends under combined loading, Int. J. Fat., 100, 627-638 (2017)

16. M. Kaffenberger, M. Vormwald, Considering size effects in the notch stress concept for fatigue assessment of welded joints. Comp. Mat. Sci., 64 , 71-78 (2012)

17. O. Hertel, M. Vormwald, Statistical and geometrical size effects in notched members based on weakest-link and short-crack modelling. Engng. Frac. Mech. 95, 72-83 (2012)

18. J. Wiebesiek, K. Störzel, T. Bruder, H. Kaufmann, Multiaxial fatigue behaviour of laserbeam-welded thin steel and aluminium sheets under proportional and nonproportional combined loading. Int J Fatigue 33, 992-1005 (2011)

19. G. Meneghetti, C. Guzzella, B. Atzori, The peak stress method combined with $3 D$ finite element models for fatigue assessment of toe and root cracking in steel welded joints subjected to axial or bending loading, Fat. Fract. Eng. Mater. Struct., 37, 722739 (2014)

20. L. Pook, A 50 year retrospective review of three-dimensional effects at cracks and sharp notches, Fat. Fract. Eng. Mater. Struct., 36, 699-723 (2013)

21. L. Pook, A. Campagnolo, F. Berto, Coupled fracture modes of discs and plates under anti-plane loading and a disc under in-plane shear loading, Fat. Fract. Eng. Mater. Struct., 39, 924-938 (2016)

22. G. Meneghetti, A. Campagnolo, V. Babini, M. Riboli, A. Spagnoli, Multiaxial fatigue assessment of welded steel details according to the peak stress method: industrial case studies, Int. J. Fat. (2019) submitted 